Das Gesetz zur Ächtung der Gewalt in der Erziehung aus dem Jahr 2000 habe - so Prof. Dr. Bussmann - bereits positive Auswirkungen gezeigt. Das Gesetz zur Erleichterung familiengerichtlicher Maßnahmen bei Gefährdung des Kindeswohls, das in diesem Jahr in Kraft trat, ermöglicht einem Familiengericht, schon bei Gefährdung des Kindeswohls in die elterliche Sorge einzugreifen. Ein darüber hinausgehendes Erziehungsversagen muss nicht mehr nachgewiesen werden. Ziel müsse es sein, unter Ausnutzung vorhandener finanzieller Ressourcen so frühzeitig wie möglich mit allen Mitteln des Jugendhilferechts auf Problemfamilien einzuwirken.

Die lebhafte und engagierte Debatte vermittelte ein umfassendes Bild des Themas. Als Resümee der Veranstaltung wurde deutlich: auf auffällig gewordene Jugendliche muss besonders aufmerksam und behutsam, zeitnah und angemessen reagiert werden. Hierzu bedarf es der Vernetzung der Verantwortlichen und einer Fortführung der bisherigen engagierten Arbeit.

(Dr. Gisa Austermühle)

\title{
Regionalgruppe Karlsruhe und Landesverband Baden-Württemberg
}

\section{Sommerempfang 2008 im Bundesgerichtshof}

Am 10. Juli 2008 fand der 6. Sommerempfang der Regionalgruppe Karlsruhe und des Landesverbands Baden-Württemberg in den Räumen des Bundesgerichtshofes statt.

Der Einladung folgten rund 100 Gäste aus Recht, Justiz und Wirtschaft, unter anderem die Vize-Präsidentin des BGH Vorsitzende Richterin am BGH Dr. Gerda Müller und Generalbundesanwalt a.D. Kay Nehm. Den Festvortrag hielt die Richterin des Bundesverfassungsgerichts Prof. Dr. Gertrude Lübbe-Wolff zum Thema „Demokratie als Weiberkram - über Antidemokratismus und Geschlechterstereotype“.

Prof. Dr. Gertrude Lübbe-Wolff studierte in Bielefeld, Freiburg und in Harvard; promovierte 1980 in Bielefeld und arbeitete dort an der Universität als wissenschaftliche Assistentin bis zu ihrer Habilitation 1987.

Sie blieb in Bielefeld und leitete das Umweltamt der Stadt. Danach war sie ab 1992 Professorin für Öffentliches Recht an der dortigen Universität.

Ab 1996 war sie Stellvertretendes Wahlmitglied des Verfassungsgerichtshofs Nordrhein-Westfalen und geschäftsführende Direktorin des Zentrums für interdisziplinäre Forschung der Universität Bielefeld.

Im Jahre 2000 wurde Prof. Dr. Gertrude Lübbe-Wolff mit dem Leibniz-Preis der Deutschen Forschungsgemeinschaft ausgezeichnet. Von 2000 bis 2002 bekleidete sie das Amt der Vorsitzenden des Rates von Sachverständigen für Umweltfragen.

Seit April 2002 ist sie Richterin des Bundesverfassungsgerichts.

Prof. Dr. Gertrude Lübbe-Wolff beleuchtete das sogenannte „Heroische Syndrom“, eine im 19. Jahrhundert und Anfang des 20. Jahrhunderts weit verbreitete Geisteshaltung, in der sich insbesondere Nationalismus und Militarismus einerseits und Antidemokratismus, Antisemitismus und Antifeminismus andererseits verbanden.

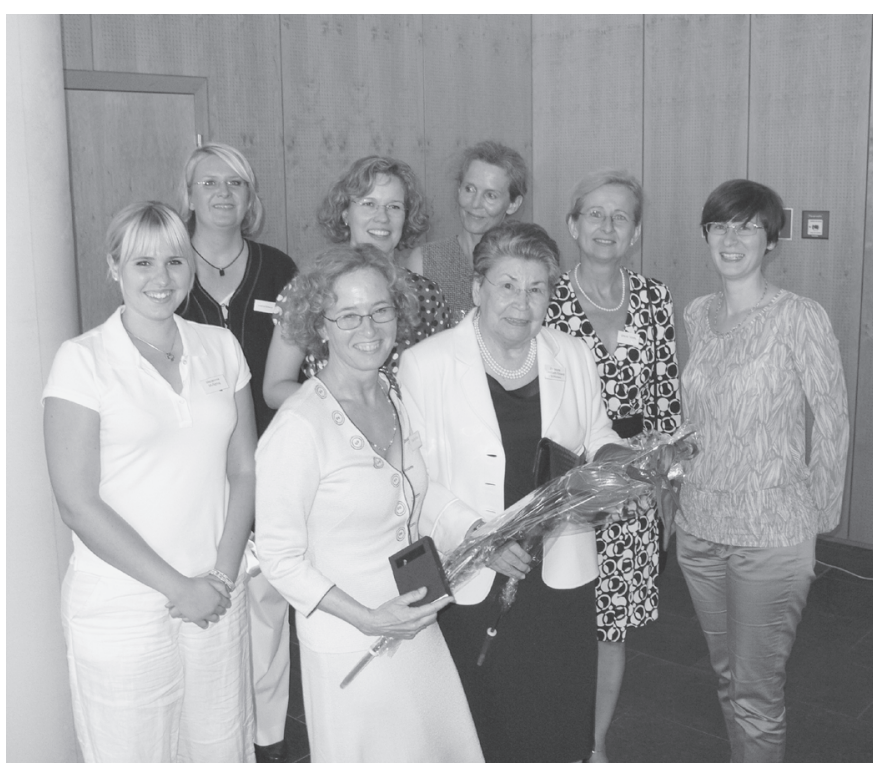

$\Delta$ Der Vorstand der Regionalgruppe Karlsruhe mit den Ehrennadelträgerinnen und der Referentin Prof. Dr. Gertrude Lübbe-Wolff. (Vordere Reihe, v.I.n.r.) Marianne Mußgnug, Eva Schübel, Dr. Marie-Elisabeth Roland-Schlosser; (Hintere Reihe v.I.n.r.) Kristina Schebur, Michaela Kistner-Burger, Prof. Dr. Gertrude Lübbe-Wolff, Ursula Görlitz, Daniela Leukert.

Im Anschluss an den Festvortrag zeichnete Rechtsanwältin Daniela Leukert, die Vorsitzende der Regionalgruppe Karlsruhe, Frau Dr. Marie-Elisabeth Roland-Schlosser - für ihre 50-jährige Mitgliedschaft - sowie ihre Vorgängerin im Amt, Bundesanwältin am BGH Eva Schübel, mit der Ehrennadel des djb aus.

Utae Nakagawa auf der Violine begleitete musikalisch den Abend, der bei interessanten Gesprächen im Innenhof des BGH ausklang. (Daniela Leukert) 